\title{
Evaluation of the Relationship of Dimensions of Maxillary Sinus Drainage System with Anatomical Variations and Sinusopathy: Cone-Beam Computed Tomography Findings
}

\author{
Gülsün Akay ${ }^{a}$ Deniz Yaman ${ }^{b}$ Özge Karadağ ${ }^{c}$ Kahraman Güngör ${ }^{a}$ \\ a Department of Oral and Dentomaxillofacial Radiology, Faculty of Dentistry, Gazi University, Ankara, Turkey; \\ ${ }^{b}$ Department of Oral and Maxillofacial Surgery, Faculty of Dentistry, Bolu Abant İzzet Baysal University, Bolu, Turkey; \\ 'Department of Statistics, Graduate School of Science and Engineering, Hacettepe University, Ankara, Turkey
}

\section{Highlights of the Study}

- A significant relationship was observed between the ostium height and the presence of maxillary sinus septa.

- Nasal septal deviation, concha bullosa, and Haller cells did not have a major effect on the length of the infundibulum and ostium height.

- The length of the infundibulum was significantly shorter in partial opacification.

- Cone-beam computed tomography images can provide valuable information for evaluating the osteomeatal complex.

\section{Keywords}

Cone-beam computed tomography - Concha bullosa . Haller cell · Nasal septal deviation - Maxillary sinus .

Osteomeatal complex

\begin{abstract}
Objective: The aim of this study was to evaluate the correlation between the length of the infundibulum and ostium height with the anatomic variations of osteomeatal complex (OMC) and sinus pathology using cone-beam computed tomography (CBCT). Methods: CBCT images of 204 patients (408 maxillary sinuses) were evaluated retrospectively. The height of the ostium and the length of the infundibulum were measured. The presence of maxillary sinus pathology, nasal septal deviation, Haller cells, concha bullosa, and sinus
\end{abstract}

septa were analyzed. The correlation between the size of the maxillary sinus drainage system and anatomic variations was compared using the $t$ test, Fisher's exact test, and $x^{2}$ test. The effect of tooth loss on the length of the infundibulum and ostium height was also analyzed using ANOVA. Results: The height of the ostium and the maximal septal deviation angle were found to be significantly greater in males $(p<0.05)$. As ostium height increased, the presence of maxillary sinus septa increased $(p<0.05)$. No statistically significant association was detected between other variations and the length of infundibulum or ostium height. The relationship between tooth loss and both the length of the infundibulum and ostium height were found to be insignificant $(p>0.05)$. Conclusions: Radiographic examination, especially on CBCT images, is important for an evaluation of maxillary sinuses. here, we demonstrated a significant relationship between ostium

\begin{tabular}{ll}
\hline KARGER & ( 2019 The Author(s) \\
Published by S. Karger AG, Basel Oparger \\
karger@karger.com & This is an Open Access article licensed under the Creative Commons \\
www.karger.com/mpp & $\begin{array}{l}\text { Attribution-NonCommercial-4.0 International License (CC BY-NC) } \\
\text { (http://www.karger.com/Services/OpenAccessLicense), applicable to } \\
\text { the online version of the article only. Usage and distribution for com- } \\
\text { mercial purposes requires written permission. }\end{array}$
\end{tabular}


height and the presence of maxillary sinus septa. However, it was found that nasal septal deviation, concha bullosa, Haller cells, and other sinusopathies did not have a major effect on the size of the maxillary sinus drainage system.

(C) 2019 The Author(s)

Published by S. Karger AG, Basel

\section{Introduction}

The osteomeatal complex (OMC) is an important anatomical entity consisting of the maxillary ostium, ethmoidal infundibulum, middle nasal concha, uncinate process, ethmoid bulla, and hiatus semilunaris [1]. $\mathrm{Mu}-$ cosal drainage in healthy tissue occurs via the OMC. In normal drainage and ventilation, the mucus reaches the ostium (maxillary sinus opening) and passes through a small passage that communicates with the nasal cavity (infundibulum) $[2,3]$. Variations that cause the narrowing of this passage have been shown to be responsible for the development of maxillary sinusitis [4]. Local anatomic variations associated with nasal septal deviation, concha bullosa, and Haller cells could cause this obstruction and sinusitis [5].

Nasal septal deviation, seen in about $80 \%$ of the population, is defined as an asymmetry of the nasal septum, and it may limit air flow and impair the growth of the paranasal sinus. As a consequence, mucosal ciliary activity decreases and bacterial invasion develops [6-8]. Additionally, previous studies stated that concha bullosa (pneumatized middle turbinate) adversely affects the paranasal sinus ventilation and mucociliary clearance in the middle meatus region [9]. However, the potential effect of nasal septal deviation and concha bullosa on the development of maxillary sinusitis has not been clarified [10]. Another anatomic variation, the presence of Haller cells, shows continuity with the infundibulum proximally [5]. If Haller cells become infected, the maxillary sinus ostium gets obstructed and chronic sinusitis results [11]. The maxillary sinus membrane (also called the Schneiderian membrane) is about $1 \mathrm{~mm}$ thick and is therefore not observed in a radiographic examination [12]. However, when the mucosa become inflamed due to infection by organisms of both odontogenic or nonodontogenic origin, this thickness may increase 10- to 15-fold [12]. Gender, smoking, the association with endodontic or periodontal lesions, and the presence of maxillary sinus septa are the factors that lead to thickening of the sinus membrane to $>3 \mathrm{~mm}$ [13-16].

The maxillary sinus is of paramount importance for oral and maxillofacial surgeons and maxillofacial radiolo- gists. Cone-beam computed tomography (CBCT) is frequently used to evaluate sinus anatomy before dental implant treatment $[15,17]$. It facilitates evaluation of the maxillofacial region with high-geometric-accuracy data, isotropic voxel values, and short scanning times $[15,18]$. It provides increased precision, lower radiation doses, and lower costs than CT $[3,18]$. Moreover, a study by $\mathrm{Al}$ Abduwani et al. [19] showed that CBCT is an efficient alternative to standard multidetector computed tomography (MDCT) to identify sinusitis. Image quality and radiation dose are comparable to MDCT.

Previous studies have evaluated the significance of anatomical variations in the pathogenesis of rhinosinusitis $[5,20,21]$. However, there is only 1 report on sinusopathies of inflammatory origin in the ostium height or the infundibulum length of the maxillary sinus [3]. The aim of this study was to investigate the effect of the length of infundibulum and ostium height on maxillary sinus pathology using CBCT images. We also assessed the effects of tooth loss, nasal septal deviation, concha bullosa, Haller cells, and the presence of maxillary sinus septa on the length of the infundibulum and ostium height.

\section{Materials and Methods}

\section{Study Samples}

A total of 204 CBCT images (408 maxillary sinuses) were selected from the archives of the Department of Oral and Maxillofacial Radiology, Faculty of Dentistry, Gazi University, between January 2016 and November 2017. The study included male and female individuals aged $\geq 18$ years who had sinus pathology with the border of both maxillary sinuses detectable on CBCT. Exclusion criteria were the presence of insufficient image quality or movement artefacts in the CBCT images; a previous history of surgery or trauma to the maxillary sinuses; and any pathology, bone graft, or dental implant adjacent to the maxillary sinus.

\section{CBCT Image Analysis}

All CBCT images were taken with a Promax 3D unit (Planmeca, Helsinki, Finland), operating at $90 \mathrm{kVp}$ and 9-14 mA (voxel size $0.2-0.4 \mathrm{~mm}$, exposure time $6 \mathrm{~s}$, and field-of-view $20 \times 10$ or $20 \times$ $17 \mathrm{~cm}$ ). The images were analyzed with a CBCT device (Romexis Viewer 4.6.2.R) on a 24-inch Nvidia Quadro FX 380 screen with $1,280 \times 1,024$ resolution in a quiet room with subdued ambient lighting. All images were evaluated by a maxillofacial radiologist with 5 years of experience. After 2 weeks, $10 \%$ of the measurements were reevaluated for intraobserver reliability (repeatability). The interobserver reliability was also assessed. Each sinus was assessed separately.

\section{Evaluation of Images}

The maxillary sinus changes were analyzed and classified as in previous studies [3, 17]; (a) normal: hypodensity; (b) mucous thickening present: an image of density in the soft parts with linear aspect in association with their walls; (c) antral pseudocyst present: 

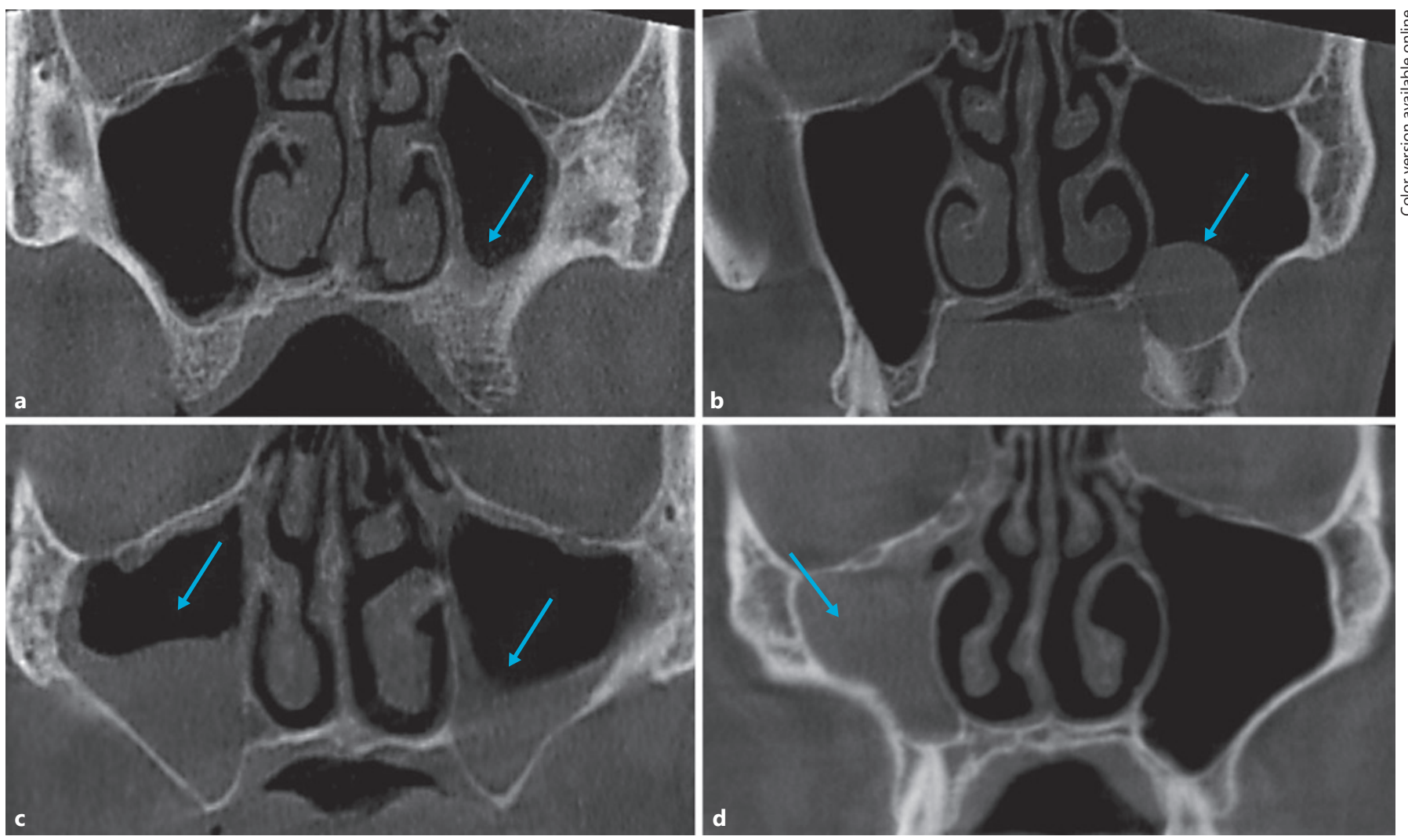

Fig. 1. Coronal CBCT images showing mucous thickening (a), antral pseudocyst (b), partial opacification (c), and total opacification (d),

an image of density in the soft parts with circular aspect in association with their walls; (d) partial opacification: an image of density in the soft parts resulting in partial opacification but presenting regions of internal hypodensity; (e) total opacification: an image of density in the soft parts resulting in total opacification (Fig. 1).

Bilateral maxilla posterior total loss and partial tooth loss were evaluated. Concha bullosa, Haller cells, maxillary sinus septa, and septal deviation were recorded (Fig. 2). Concha bullosa was defined as the presence of pneumatization of any size on the left or right within the middle nasal turbinate. Nasal septal deviation was defined as a deviation of the midline to the left or right. Haller cells were detected as ethmoid air cells located along the medial orbital floor above the maxillary sinus ostium and extending into the sinus. Maxillary sinus septa were described as the walls of cortical bone within the maxillary sinus, and the type (i.e., primary or secondary) was assessed. The length of the infundibulum was measured as the distance between the center of the ostium and the uppermost point of the uncinate process in a coronal slice of the CBCT image. The ostium height was measured from the center of the maxillary sinus ostium, thus determining the distance (in millimeters) between the ostium and the lowest point of the corresponding maxillary sinus [3] (Fig. 3).

\section{Statistical Analysis}

All statistical analysis was performed using IBM-SPSS software v23.0 (Armonk, NY, USA). Statistical analysis was conducted with descriptive statistics. The effect of age and gender on the anatomi- cal variations and sinus pathology were analyzed by $\chi^{2}$ test and Fisher's exact test. The effect of gender on measurements was analyzed by an independent samples $t$ test and the nonparametric Mann-Whitney U test, depending on the distribution of the measurement. The independent samples $t$ test was also used to compare the mean measurements (infundibulum length and ostium height) in the presence and the absence of sinus pathologies. The relationship between sinus pathology and anatomical variations was analyzed using Fisher's exact test. The effect of tooth loss on the length of the infundibulum and ostium height was also analyzed with ANOVA. The relationship between tooth loss and type of septum (primary or secondary) was analyzed with Pearson's $\chi^{2}$ test. The significance level was set to 0.05 . For intraobserver repeatability and interobserver reproducibility, intraclass correlation coefficients (ICCs) were calculated.

\section{Results}

The images included in the study were 408 maxillary sinus CBCT images taken from individuals aged 18-78 years. Of the images, $52.5 \%(n=107)$ were taken from females and $47.5 \%(n=97)$ from males. Most of the measurements were taken from the maxillary sinus bilaterally. 

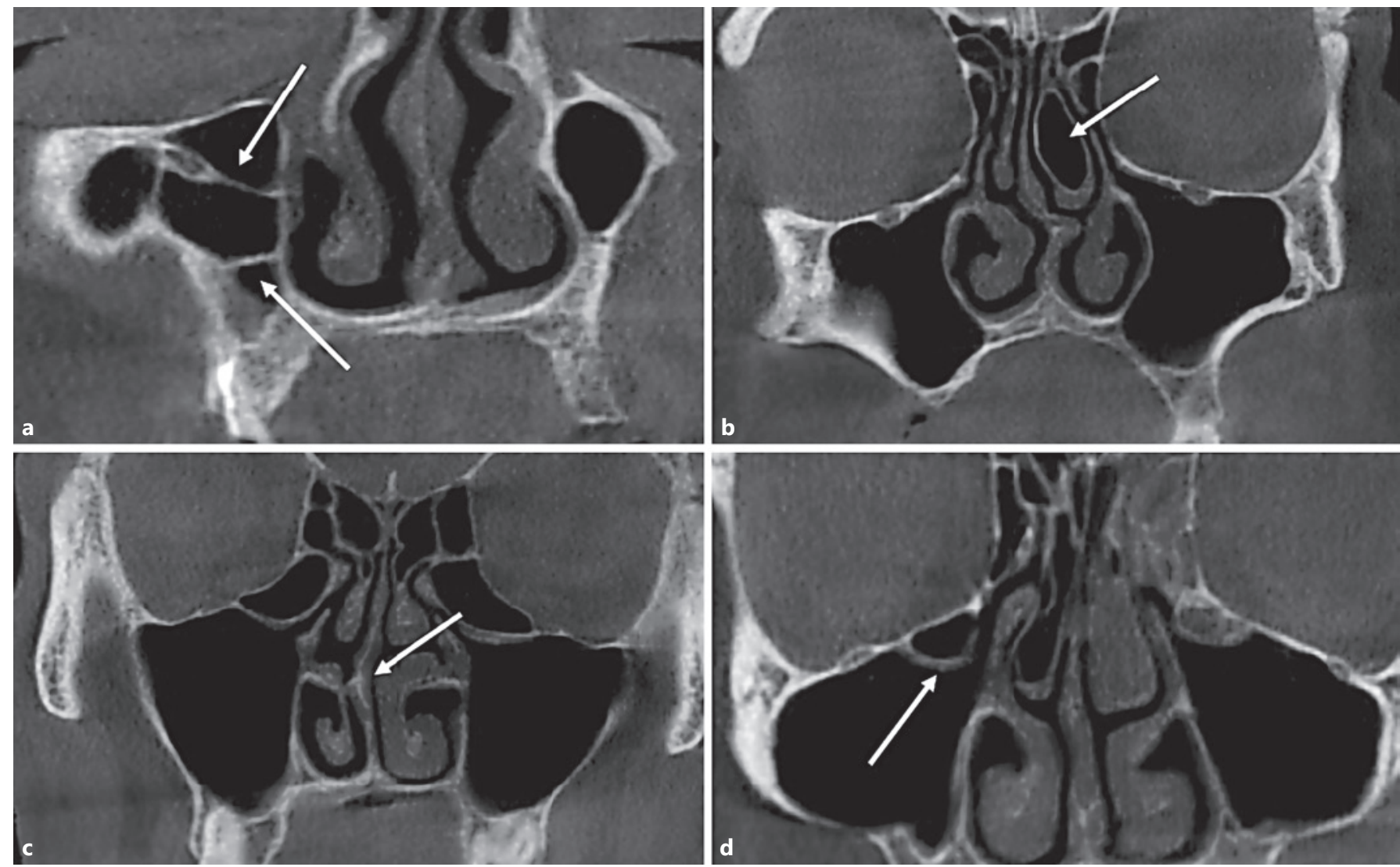

Fig. 2. Coronal CBCT images showing maxillary sinus septa (a), concha bullosa (b), septal deviation (c), and Haller cells (d).
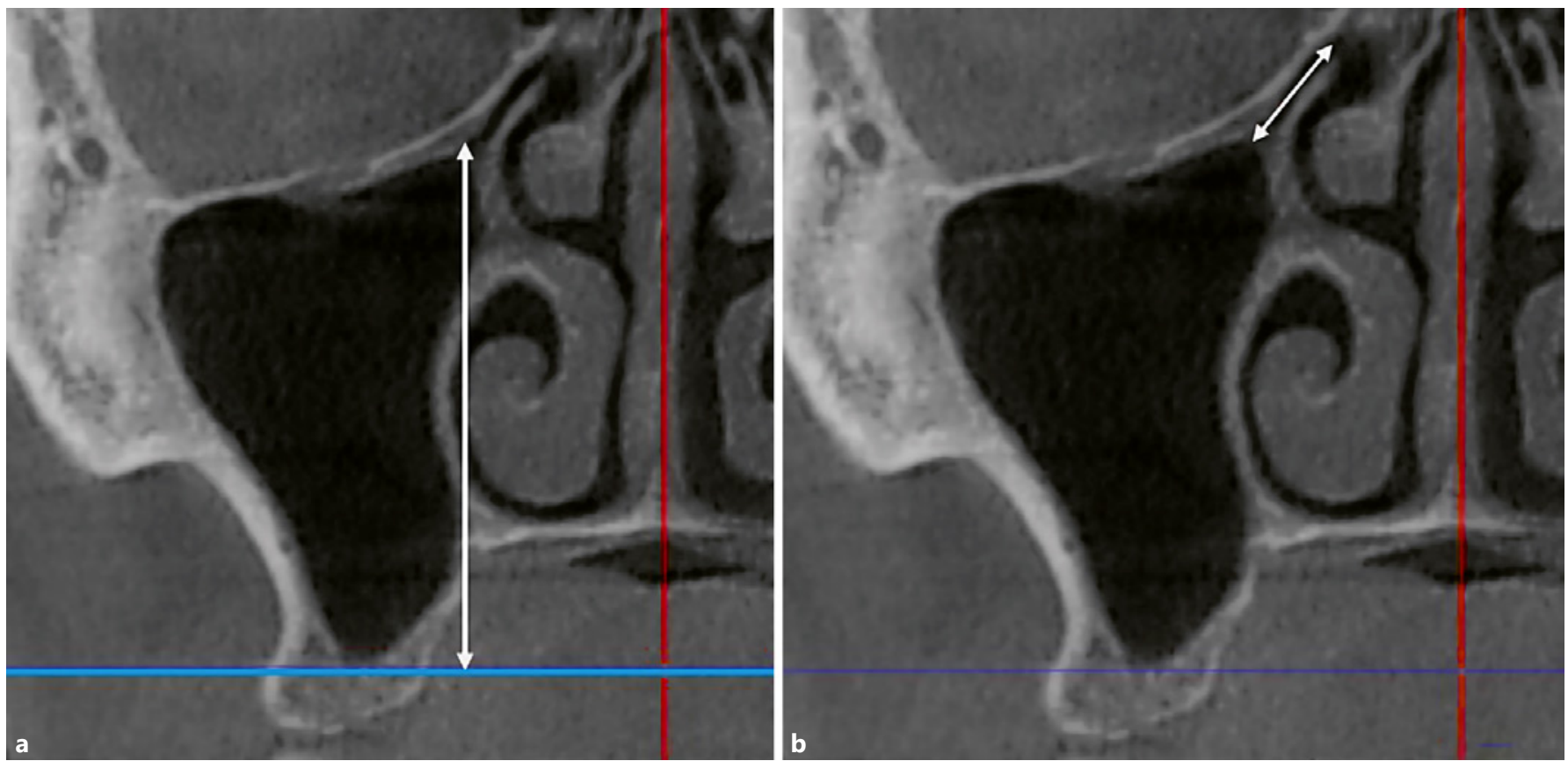

Fig. 3. Coronal CBCT images showing the ostium height (a) and infundibulum length (b) of the maxillary sinus. 
Table 1. Distribution of the presence of anatomical variations and maxillary sinus pathology according to age group and gender

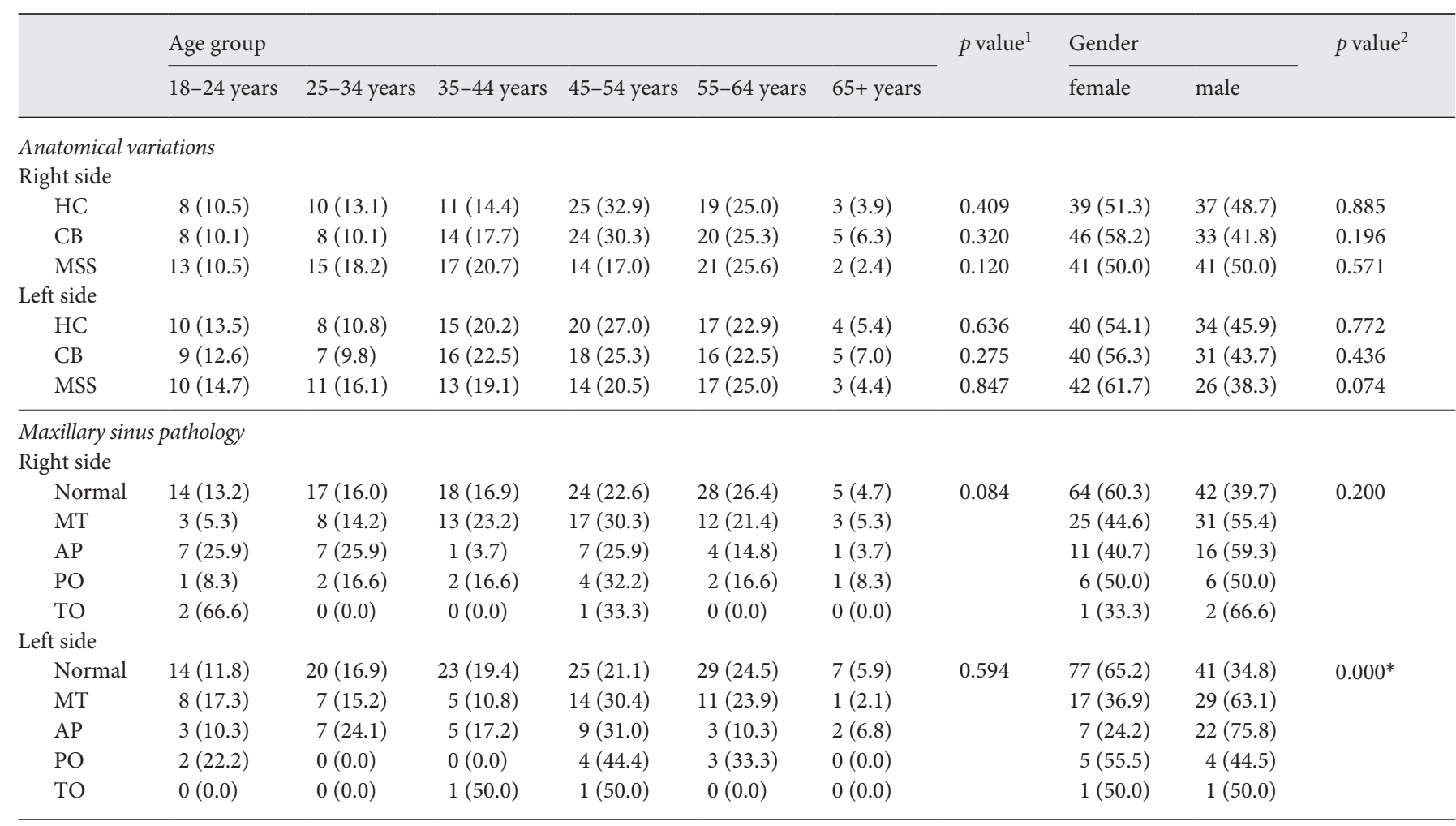

Values express $n(\%) . *$ Significant at $\alpha=0.05$. HC, Haller cells; CB, concha bullosa; MSS, maxillary sinus septa; MT, mucous thickening; AP, antral pseudocyst PO; partial opacification; TO, total opacification.

${ }^{1}$ With the $\chi^{2}$ test; ${ }^{2}$ with Fisher's exact test.

Table 2. Mean values and standard deviation of infundibulum length and ostium height according to gender

\begin{tabular}{llclc}
\hline & Gender & Mean & Standard deviation & $p$ value \\
\hline Infundibulum length (right) & female & 7.32 & 2.02 & $0.546^{1}$ \\
& male & 7.53 & 2.62 & $0.816^{1}$ \\
\hline Infundibulum length (left) & female & 6.98 & 2.30 & $0.000^{1, *}$ \\
& male & 7.06 & 2.24 & \\
\hline Ostium height (right) & female & 29.40 & 5.16 & $0.000^{1, *}$ \\
& male & 32.41 & 6.02 & \\
\hline Ostium height (left) & female & 30.41 & 5.01 & \\
& male & 33.47 & 6.36 & \\
\hline
\end{tabular}

* Significant at $\alpha=0.05$.

${ }^{1}$ With the $t$ test; ${ }^{2}$ with the Mann-Whitney U test.

The effect of age and gender on anatomical variations and sinus pathology were analyzed. The $p$ values showed there was no statistically significant relationship with age and gender for the presence of Haller cells, concha bullosa, and sinus septa. The effect of gender on the presence of sinus pathology was found to be statistically significant for the left maxillary sinus (Table 1). The effect of gender on measurements (infundibulum length and ostium height) was analyzed. Our results showed there were statistically significant differences between males and fe- 
Table 3. Mean values and standard deviations for infundibulum length and ostium height in sinus pathologies and normal maxillary sinuses

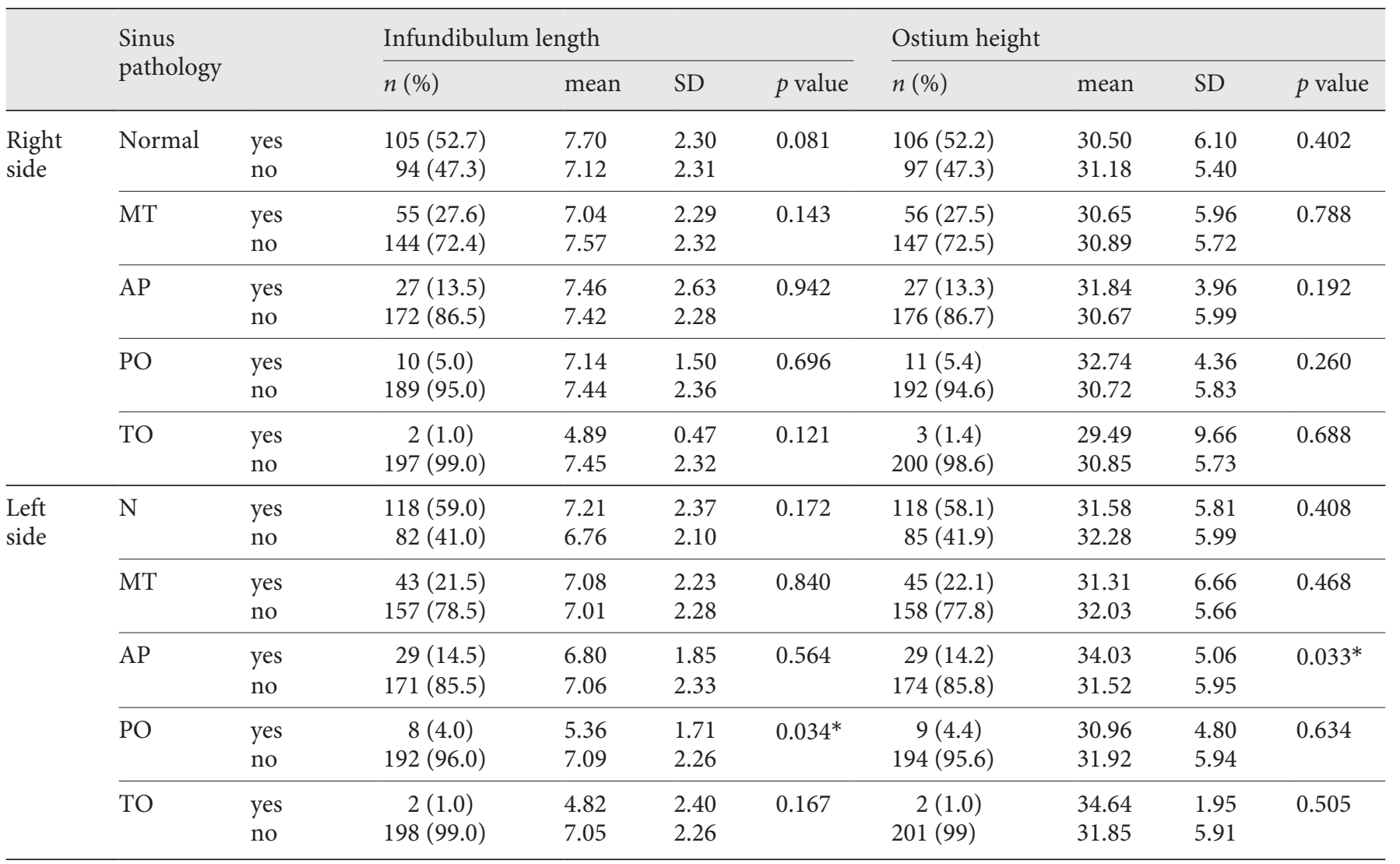

* Significant at $\alpha=0.05$. SD, standard deviation; MT, mucous thickening; AP, antral pseudocyst; PO, partial opacification; TO, total opacification.

males in terms of ostium height. The mean values were high for males compared to females. On the other hand, the effect of gender on the length of the infundibulum for both maxillary sinuses was insignificant (Table 2).

To compare the effect of the presence or absence of sinus pathology on infundibulum length and ostium height, independent samples $t$ tests were used. The results of the comparison of infundibulum length and ostium height according to sinus pathology are given in Table 3. The effect of the presence or absence of anatomical variations on the infundibulum length and ostium height were also compared. There was a significant relationship between the ostium height and the presence of sinus septa. The $t$ test results for the infundibulum length and ostium height are presented in Table 4. The relationship between the presence of sinus pathology and anatomical variations was analyzed using Fisher's exact test. The results showed that septal deviation,
Haller cells, concha bullosa, and sinus septa did not have a significant influence on the presence of maxillary sinus pathology.

The relationship between tooth loss and the length of the infundibulum and ostium height was also analyzed. The relationship between tooth loss and both the length of the infundibulum and height of the ostium was found to be insignificant. The relationship between tooth loss and the type of septa (primary or secondary) was analyzed with Pearson's $\chi^{2}$ test and was found to be statistically significant. On the other hand, the correlation between gender and type of septum was not significant. To evaluate intraobserver reliability, the images of 25 patients were reevaluated after 2 weeks. ICCs were calculated to assign to the agreement levels and ranged between 0.88 and 0.92 , which indicates strong agreement. The interobserver reliability was also assessed using ICCs and the results were highly correlated (0.82-0.94). 
Table 4. Mean values and standard deviations for infundibulum length and ostium height in anatomical variations

\begin{tabular}{|c|c|c|c|c|c|c|c|c|c|c|}
\hline & \multirow[t]{2}{*}{ Variable } & \multirow[t]{2}{*}{ Present } & \multicolumn{4}{|c|}{ Infundibulum length } & \multicolumn{4}{|c|}{ Ostium height } \\
\hline & & & $n(\%)$ & mean & SD & $p$ value & $n(\%)$ & mean & $\mathrm{SD}$ & $p$ value \\
\hline \multirow{5}{*}{$\begin{array}{l}\text { Right } \\
\text { side }\end{array}$} & & no & $122(61.7)$ & 7.21 & 2.22 & & $126(62.7)$ & 31.20 & 5.94 & \\
\hline & $\mathrm{CB}$ & yes & 77 (38.9) & 7.42 & 2.18 & 0.913 & $79(39.1)$ & 31.52 & 5.73 & 0.190 \\
\hline & & no & $119(59.8)$ & 7.49 & 2.25 & & $121(59.6)$ & 29.86 & 5.66 & \\
\hline & NSD & yes & $68(34.2)$ & 7.13 & 2.42 & 0.195 & $70(34.5)$ & 30.79 & 5.65 & 0.953 \\
\hline & & no & $131(65.8)$ & 7.58 & 2.26 & & $133(65.5)$ & 30.84 & 5.85 & \\
\hline \multirow{5}{*}{$\begin{array}{l}\text { Left } \\
\text { side }\end{array}$} & $\mathrm{HC}$ & yes & $74(37.0)$ & 7.35 & 2.41 & 0.115 & $74(36.5)$ & 32.64 & 4.84 & 0.131 \\
\hline & MSS & yes & $68(34.0)$ & 7.37 & 2.52 & 0.118 & $68(33.5)$ & 33.16 & 5.19 & $0.027^{*}$ \\
\hline & & no & $132(66.0)$ & 6.84 & 2.12 & & $135(66.5)$ & 31.23 & 6.12 & \\
\hline & NSD & yes & $83(41.5)$ & 7.06 & 2.31 & 0.866 & 85 (41.9) & 32.54 & 6.20 & 0.174 \\
\hline & & no & $117(58.5)$ & 7.00 & 2.24 & & $118(58.1)$ & 31.40 & 5.63 & \\
\hline
\end{tabular}

* Significant at $\alpha=0.05$. SD, standard deviation; HC, Haller cells; CB, concha bullosa; MSS, maxillary sinus septa; NSD, nasal septal deviation.

\section{Discussion}

The maxillary sinus is a significant anatomical structure in maxillofacial surgery. The evaluation of maxillary sinus size and pathology can be of great value to the operator before dental implant planning and sinus floor elevation [13, 16]. The shape of the maxillary sinus may also cause anatomical limitations to implant surgery [22]. Therefore, precise visualization of anatomic variations and pathologies of the maxillary sinus and adjacent structures is vital to prevent possible complications during surgery. CBCT is an effective method for detecting radiodensities in the maxillary sinus, and it provides significant advantages for radiologists due to its high spatial resolution [2]. We focused on evaluating CBCT images to ascertain whether there was any relationship between maxillary sinus pathology and OMC variations such as the presence of concha bullosa, Haller cells, nasal septal deviation, and maxillary sinus septa, with infundibulum length and ostium height.

The prevalence of maxillary sinus pathology according to age and gender was investigated. Our results demonstrated that there was no significant association between age and sinus pathology. Although the incidence of max- illary sinus pathology increased in the age groups of 4554 and 55-64 years, this result was not statistically significant for both sides of the maxillary sinus. This result is in line with that of Janner et al. [23]. They observed that mucosal thickening was associated with gender, but that age and periapical status were not the parameters of this relationship. Our results showed that mucosal thickening and antral pseudocyst were the most common maxillary sinus pathologies bilaterally.

In this study, the presence of radiodensities in the maxillary sinus was found in 184 of the 408 sinuses (45.1\%), considerably higher than reported in the literature [22]. On the other hand, the prevalence rate of sinus mucosal thickening was found to be $25 \%$ ( $n=102$ maxillary sinuses), which is much lower than in other studies (range 37-62\%) [15, 17, 23, 24]. These variations between studies may be due to differences in the measurements considered to be mucosal thickening $(>1,>2$, or $>3 \mathrm{~mm})$. We accepted $\geq 2 \mathrm{~mm}$ as mucosal thickening.

The maxillary sinuses are directly related to the roots of the upper teeth and are affected by inflammatory odontogenic processes that change the sinus content and normal physiology $[3,15,24]$. Therefore, we excluded patients 
with periapical inflammatory and periodontal disease in the maxillary posterior teeth. In previous studies, the presence of periapical lesions, periodontal bone loss, root canal filling, and the anatomical relationship between maxillary sinuses and teeth were evaluated in terms of their possible effects on the maxillary sinuses [12, 24]. However, to our knowledge, there is only 1 study on the existence of sinusopathies of inflammatory origin in the ostium height or the infundibulum length of the maxillary sinus [3]. We investigated the relationship between ostium height and infundibulum length with sinus pathology. The effect of gender on sinus pathology was found to be statistically significant only for the left side of the maxilla. In addition, a high preponderance of mucosal thickening was observed in males and older age groups (45-54 and 55-64 years). Antral pseudocysts were found to be more prevalent in males and younger age groups ( $<65$ years). Similar to the results of our study, Sheikhi et al. [12] revealed a higher prevalence of mucosal thickening among males.

A previous study found that a shorter ostium and infundibulum facilitate the drainage of sinus contents [3]. Ostium height was found to be a determining factor for the presence of normal content in the maxillary sinus; it was also significant with greater height and antral pseudocyst. In our study, infundibulum length and ostium height were found to be greater in males than in females. There were significant differences between the genders regarding ostium height but not regarding infundibulum length. In contrast to the results of de Carvalho et al. [3], we found that the infundibulum was significantly shorter with the sinus pathology partial opacification. Additionally, we found that as ostium height increased, the presence of antral pseudocyst increased. This discrepancy between studies probably resulted from differences in the inclusion criteria, measurements techniques, and ethnicities of the study populations.

We also aimed to investigate the prevalence of nasal septal deviation. Nasal septal deviation causes congestion of the middle concha, blockage of the middle meatus, and the obstruction of normal mucus flow from the sinuses [13]. Thus, nasal septal deviations are a predisposing factor for obstruction and related complications [5]. Holton et al. [25] reported that nasal septal deviations are associated with the hard palate and lateral wall asymmetry of the nasal cavity. The incidence of nasal septal deviation has been examined in different studies and found to be in the range of $9-79.9 \%[8,13]$. In our study, we found an incidence of 74\%. Sapmaz et al. [6] found that nasal septal deviation leads to reduced maxillary sinus volume on the deviated side. Our results revealed no significant relation-

Maxillary Sinus Drainage System and Anatomical Variations ship between nasal septal deviation and infundibulum length or ostium height.

Previous studies investigated the effects of anatomical variations on sinus pathology $[5,10,11,20,21,26]$. Kaygusuz et al. [20] evaluated the relation between chronic rhinosinusitis and sinonasal anatomic variations. They showed no statistically significant correlation between sinonasal anatomic variations and chronic rhinosinusitis. Stallman et al. [10] demonstrated no statistical association between the anatomical variations and sinus disease. Our results are compatible with these studies; relationships between the presence of septal deviation, Haller cells, concha bullosa, and sinus septa with maxillary sinus pathology were not significant.

We also investigated anatomical variations such as Haller cells, concha bullosa, and sinus septa and their possible influence on infundibulum length and ostium height. Alkire and Bhattacharyya [26] reported that the presence of Haller cells and a smaller infundibulum width were related to the progress of recurrent acute rhinosinusitis. Shin et al. [21] found that the presence of concha bullosa was significantly associated with maxillary sinus fungal ball development, and that a narrow long infundibulum can play a role in the development of this pathogenesis. Tonai and Baba [9] showed Haller cells in the study with a rate of $36 \%$. Another study reported Haller cells with a rate of $39.9 \%$ [26]. We detected Haller cells with a rate of approximately $37 \%$. This finding is in line with the other 2 studies $[9,26]$. Haller cells are located inferior to the ethmoid bulla and adjacent to the roof of the maxillary sinus, continuing with the proximal infundibulum. Particularly when these cells are infected, they narrow the ostium of the maxillary sinus and adversely affect drainage [11]. However, our study revealed there was no statistically significant correlation between the presence of Haller cells and infundibulum length or ostium height. There was also no relationship found between the presence of Haller cells and sinus pathology. Another local anatomic variation, concha bullosa, was seen in $36.8 \%$ of our cases, which is lower than in previous reports $[10,26]$. Although the concha bullosa is accepted as an etiological factor in sinusitis, our findings did not corroborate this relationship. We found a slightly higher incidence of concha bullosa in females than in males.

Maxillary sinus septa is one of the most studied subjects in terms of location, prevalence, and morphology [27-29]. Maxillary sinus septa was found in $49 \%$ of patients, on the right $(40.2 \%)$ and left $(33.4 \%)$ sides, higher than reported by Kim et al. [27], Neugebauer et al. [28], but lower than reported by Neychev et al. [29]. This difference could be associated with the different radiograph- 
ic examinations, the thin interval slice of the CBCT images (in this study, $0.2-0.4 \mathrm{~mm}$ ), and the different ages of the study populations. Neugebauer et al. [28] and Neychev et al. [29] found no correlation between gender and the prevalence of septa. Our results showed a nonsignificant relationship between the prevalence of septa and gender or age. However, there was a statistically significant relationship between ostium height and the presence of sinus septa. We also investigated the type of septa and assessed the relationship between tooth loss, infundibulum length, and ostium height. Neychev et al. [29] reported that primary complete septa were found in patients with teeth, and secondary partial septa were observed in edentulous patients; in our study, the edentulous patients were found to have a higher prevalence of septa. Our results showed a statistically significant difference between the septa type in toothed and edentulous regions of the maxilla. The effect of the absence or presence of teeth on the length of the infundibulum and ostium height was also assessed. However, no statistically significant relationship was detected between tooth loss and the length of the infundibulum or the height of the ostium.

\section{Conclusions}

Our study indicates that the OMC has a very high rate of anatomical variations. Nasal septal deviation, concha bullosa, Haller cells, and some sinusopathies had no ma- jor effects on the size of the maxillary sinus drainage system (infundibulum length and ostium height). However, there was a significant relationship between ostium height and the presence of maxillary sinus septa. Anatomic variations of maxillary sinuses should be analyzed and interpreted accurately. When planning any surgical procedure, especially dental implant surgery, careful CBCT assessment of septa incidence and OMC is necessary. CBCT images can provide valuable information to clinicians for evaluating the OMC. Multicenter studies with a larger number of cases are still needed to assess the correlation between the sinus drainage system and sinus pathology with anatomical variations.

\section{Statement of Ethics}

The study protocol was approved by the Ethics Review Board of Gazi University (No. 2018-407). All procedures followed were in accordance with the ethical standards of the responsible committee on human experimentation (institutional and national) and with the Helsinki Declaration of 1964 and later versions. Informed consent was obtained from patients for being included in the study.

\section{Disclosure Statement}

All authors declare that they do not have any conflicts of interests.

\section{References}

1 Tomomatsu N, Uzawa N, Aragaki T, Harada K. Aperture width of the osteomeatal complex as a predictor of successful treatment of odontogenic maxillary sinusitis. Int J Oral Maxillofac Surg. 2014 Nov;43(11):1386-90.

2 Parks ET. Cone beam computed tomography for the nasal cavity and paranasal sinuses. Dent Clin North Am. 2014 Jul;58(3):627-51.

3 de Carvalho AB, Ferreira Costa AL, Fuziy A, de Assis AC, Castro Veloso JR, Coutinho Manhães LR, et al. Investigation on the relationship of dimensions of the maxillary sinus drainage system with the presence of sinusopathies: a cone beam computed tomography study. Arch Oral Biol. 2018 Oct;94:78-83.

4 Bell GW, Joshi BB. Macleod RI. Maxillary sinus disease: diagnosis and treatment. Br Dent J. 2011;210(3):113-8.

5 Aramani A, Karadi RN, Kumar S. A study of anatomical variations of osteomeatal complex in chronic rhinosinusitis patients-CT findings. J Clin Diagn Res. 2014 Oct;8(10):KC0104.
6 Sapmaz E, Kavaklı A, Sapmaz HI, Ögetürk M. Impact of hard palate angulation caused by septal deviation on maxillary sinus volume. Turk Arch Otorhinolaryngol. 2018 Jun;56(2): 75-80.

7 Serifoglu I, Oz II, Damar M, Buyukuysal MC, Tosun A, Tokgöz Ö. Relationship between the degree and direction of nasal septum deviation and nasal bone morphology. Head Face Med. 2017;28;13(1):3.

8 Kucybała I, Janik KA, Ciuk S, Storman D, Urbanik A. Nasal septal deviation and concha bullosa - do they have an impact on maxillary sinus volumes and prevalence of maxillary sinusitis? Pol J Radiol. 2017 Mar;82:126-33.

9 Tonai A, Baba S. Anatomic variations of the bone in sinonasal CT. Acta Otolaryngol Suppl. 1996;525:9-13.

10 Stallman JS, Lobo JN, Som PM. The incidence of concha bullosa and its relationship to nasal septal deviation and paranasal sinus disease. AJNR Am J Neuroradiol. 2004 Oct;25(9): 1613-8.
11 Lloyd GA, Lund VJ, Scadding GK. CT of the paranasal sinuses and functional endoscopic surgery: a critical analysis of 100 symptomatic patients. J Laryngol Otol. 1991 Mar; 105(3):181-5.

12 Sheikhi M, Pozve NJ, Khorrami L. Using cone beam computed tomography to detect the relationship between the periodontal bone loss and mucosal thickening of the maxillary sinus. Dent Res J (Isfahan). 2014 Jul;11(4):495501.

13 Bayrak S, Ustaoğlu G, Demiralp KÖ, Kurşun Çakmak EŞ. Evaluation of the characteristics and association between schneiderian membrane thickness and nasal septum deviation. J Craniofac Surg. 2018 May;29(3): 683-7.

14 Çakur B, Sümbüllü MA, Durna D. Relationship among Schneiderian membrane, Underwood's septa, and the maxillary sinus inferior border. Clin Implant Dent Relat Res. 2013 Feb;15(1):83-7. 
15 Lu Y, Liu Z, Zhang L, Zhou X, Zheng Q, Duan $\mathrm{X}$, et al. Associations between maxillary sinus mucosal thickening and apical periodontitis using cone-beam computed tomography scanning: a retrospective study. J Endod. 2012 Aug;38(8):1069-74.

16 van den Bergh JP, ten Bruggenkate CM, Disch FJ, Tuinzing DB. Anatomical aspects of sinus floor elevations. Clin Oral Implants Res. 2000 Jun;11(3):256-65.

17 Ritter L, Lutz J, Neugebauer J, Scheer M, Dreiseidler T, Zinser MJ, et al. Prevalence of pathologic findings in the maxillary sinus in cone-beam computerized tomography. Oral Surg Oral Med Oral Pathol Oral Radiol Endod. 2011 May;111(5):634-40.

18 Scarfe WC, Farman AG, Sukovic P. Clinical applications of cone-beam computed tomography in dental practice. J Can Dent Assoc. 2006 Feb;72(1):75-80.

19 Al Abduwani J, ZilinSkiene L, Colley S, Ahmed S. Cone beam CT paranasal sinuses versus standard multidetector and low dose multidetector CT studies. Am J Otolaryngol. 2016 Jan-Feb;37(1):59-64.
20 Kaygusuz A, Haksever M, Akduman D, Aslan S, Sayar Z. Sinonasal anatomical variations: their relationship with chronic rhinosinusitis and effect on the severity of disease-a computerized tomography assisted anatomical and clinical study. Indian J Otolaryngol Head Neck Surg. 2014 Sep;66(3):260-6.

21 Shin JM, Baek BJ, Byun JY, Jun YJ, Lee JY. Analysis of sinonasal anatomical variations associated with maxillary sinus fungal balls. Auris Nasus Larynx. 2016 Oct;43(5):524-8.

22 Kawai T, Tanaka R, Yeung AW, von Arx T, Bornstein MM. Frequency and type of incidentally detected radiodensities in the maxillary sinus: a retrospective analysis using cone beam computed tomography (CBCT). Clin Oral Investig. 2019 Mar;23(3):1091-9.

23 Janner SF, Caversaccio MD, Dubach P, Sendi $\mathrm{P}$, Buser D, Bornstein MM. Characteristics and dimensions of the Schneiderian membrane: a radiographic analysis using cone beam computed tomography in patients referred for dental implant surgery in the posterior maxilla. Clin Oral Implants Res. 2011 Dec;22(12):1446-53.

24 Aksoy U, Orhan K. Association between odontogenic conditions and maxillary sinus mucosal thickening: a retrospective CBCT study. Clin Oral Investig. 2019 Jan;23(1):12331.
25 Holton NE, Yokley TR, Figueroa A. Nasal septal and craniofacial form in European- and African-derived populations. J Anat. 2012 Sep;221(3):263-74.

26 Alkire BC, Bhattacharyya N. An assessment of sinonasal anatomic variants potentially associated with recurrent acute rhinosinusitis. Laryngoscope. 2010 Mar;120(3):631-4.

27 Kim MJ, Jung UW, Kim CS, Kim KD, Choi $\mathrm{SH}$, Kim CK, et al. Maxillary sinus septa: prevalence, height, location, and morphology. A reformatted computed tomography scan analysis. J Periodontol. 2006 May;77(5):9038.

28 Neugebauer J, Ritter L, Mischkowski RA, Dreiseidler T, Scherer P, Ketterle M, et al. Evaluation of maxillary sinus anatomy by cone-beam CT prior to sinus floor elevation. Int J Oral Maxillofac Implants. 2010 MarApr;25(2):258-65.

29 Neychev D, Kanazirska P, Simitchiev K, Yordanov G. CBCT images: an important tool in the analysis of anatomical variations of maxillary sinus related to Underwood septa features. Biotechnol Biotechnol Equip. 2017; 31(6):1210-5. 